\title{
Selection priority for harvested trees according to stand structural indices
}

\author{
Yuanfa Li ${ }^{(1)}$, \\ Gangying Hui (2), \\ Hongxiang Wang (2), \\ Gongqiao Zhang ${ }^{(2)}$, \\ Shaoming Ye ${ }^{(1)}$
}

\begin{abstract}
The selection of trees to be harvested is a core tenet of uneven-aged forest management; however, few studies have focused on the process of tree selection. A set of stand structural parameters (uniform angle index, $W$; mingling index, $M$; dominance index, $U$ ) based on tree neighbor-spatial relationships, are particularly suitable for expressing the structural characteristics of forest stands. Such indices were used to parameterize thinning in three plots (a-c, each $100 \times 100 \mathrm{~m}^{2}$ ) in a Korean pine broad-leaved forest in northeastern China and one plot $\left(\mathrm{h}, 70 \times 70 \mathrm{~m}^{2}\right)$ in a pine-oak mixed forest in northwest China. Low-intensity single-tree selection was applied according to the principles of structure-based forest management (SBFM), i.e., to promote high mixture, obvious size differentiation, and random pattern with the aim of improving the overall structure of the managed plots. A group of thinning priority indices $\left(v \_i j, k_{-} i j\right.$ and $\left.z_{-} i j\right)$ were calculated according to the bivariate distributions of the structural characteristics of harvested trees and stands before harvest. Our results demonstrated that $v_{-} i j, k_{-} i j$ and $z_{-} i j$ adequately describe the spatial relationship between each tree and its nearest neighbors, and their combinations can be efficiently used to set thinning priorities on harvested trees with different structural characteristics. Their application can reduce the subjectivity of the selection process and improve the speed and accuracy of the choice of trees to be harvested in uneven-aged mixed forests.
\end{abstract}

Keywords: Dominance Index, Mingling Index, Thinning, SBFM, Silviculture, Uneven-aged Forest, Uniform Angle Index

amount of rainfall that reaches the understory (Mazza et al. 2011, Dung et al. 2012, Qiu et al. 2013), an acceleration of soil nutrient cycles (McHenry et al. 2006, Nahm et al. 2006), and reductions in the occurrence of forest fires, plant diseases, and insect pests (Nowak et al. 2008). However, thinning may sometimes result in counterproductive outcomes (Mäkinen \& Isomäki 2004), such as damaging understory, increasing the risk of natural disasters, decreasing the increment of total accumulation and seedling survival rate (Myers et al. 2000, Del Río et al. 2008), inhibiting seed germination (Kyereh et al. 1999, Tao et al. 2016), even reducing tree species diversity (O'Hara 2007). The resulting changes may
(1) College of Forestry, Guangxi University, Daxue East Road 100, Xixiangtang District, Nanning, Guangxi Province 530004 (China); (2) Key Laboratory of Tree Breeding and Cultivation, State Forestry Administration, Research Institute of Forestry, Chinese Academy of Forestry, Box 1958, Beijing 100091 (China)

@ Shaoming Ye (yshaoming@163.com)

Received: May 16, 2016 - Accepted: Feb 19, 2017

Citation: Li Y, Hui G, Wang H, Zhang G, Ye S (2017). Selection priority for harvested trees according to stand structural indices. iForest 10: 561-566. - doi: 10.3832/ifor2115-010 [online 2017-05-05]

Communicated by: Giorgio Alberti negatively affect stand growth and harvesting.

The selection of trees to be harvested is at the core of thinning. The process of selection is restricted by a number of factors. On the one hand, the thinning process is irreversible and difficult to repeat, and even successful outcomes cannot provide a very specific operational standard since such a standard may be difficult to apply in other forest management contexts (Kang 2011). On the other hand, thinning is a poorly defined concept. The ambiguity is caused by many factors, such as vague definitions, artificial intervention, and the accuracy of survey data. Definitions that do not accurately describe existing operations cannot be used to predict future thinning effects (Gadow \& Hui 1998).

Recently, uneven-aged forest management, and other management methods that strongly emphasize recovery or preservation of complex stand structures have been strongly advocated (Lindenmayer et al. 2000, Franklin et al. 2007, Gronewold et al. 2010). These demand that changes in stand density, structure, and value produced by thinning are to be objectively considered (Mäkinen \& Isomäki 2004), especially with regard to the choice of appropriate trees to harvest. In practice, when a tree is selected as a candidate for logging, foresters must investigate many factors, such as logging accessibility, spa- 
Tab. 1 - Stand features of the four measured plots (a, b, c, h).

\begin{tabular}{cclcccccc}
\hline Plot & $\begin{array}{c}\text { Slope } \\
\left({ }^{\circ}\right)\end{array}$ & $\begin{array}{l}\text { Slope } \\
\text { aspect }\end{array}$ & $\begin{array}{c}\text { Density } \\
(\text { Trees/ha) }\end{array}$ & $\begin{array}{c}\text { Mean } \\
\text { Altitude } \\
(\mathbf{m})\end{array}$ & $\begin{array}{c}\text { Canopy } \\
\text { cover }\end{array}$ & $\begin{array}{c}\text { Mean } \\
\text { DBH } \\
(\mathbf{c m})\end{array}$ & $\begin{array}{c}\text { Basal } \\
\text { area } \\
\left(\mathbf{m}^{2}\right)\end{array}$ & $\begin{array}{c}\text { Number } \\
\text { of } \\
\text { species }\end{array}$ \\
\hline a & 17 & Northwest & 1178 & 600 & 0.85 & 14.67 & 30.42 & 20 \\
b & 9 & Northwest & 797 & 600 & 0.90 & 18.34 & 31.67 & 19 \\
c & 9 & Northwest & 816 & 600 & 0.90 & 17.71 & 29.56 & 22 \\
h & 12 & West & 933 & 1720 & 0.90 & 15.8 & 27.85 & 33 \\
\hline
\end{tabular}

tial distribution, degree of mixture in the residual stand, seed input in the residual stand, wood quality and market value, species life traits and response to crowding, health status, and biodiversity concerns, e.g., whether the tree is a protected or keystone species (Mills et al. 1993, Ma 1999, Lyons et al. 2004), or whether other organisms are dependent on it (Kuuluvainen et al. 1996). A comprehensive approach to select candidate tree must use a combination of thinning-relevant variables to calculate the probability of removing a particular tree (Gadow \& Hui 1998). All trees are then ranked, and those with maximum probability are removed. This method of tree selection seems reasonable, but its implementation is cumbersome. It is impossible for operators to decide whether a tree should be cut or not by comparing all trees in a plot, even in forest stands with simplified structures (Gadow \& Hui 1998). Other thinning methods are available for uneven-aged forest management practices but these also have obvious weaknesses. Approaches include the stem number guide curve (Gadow et al. 2012), the Avance. ships between adjacent trees. value thinning method (Gadow \& Hui 1998), and the diameter-limit cut (Schulte \& Buongiorno 1998). These approaches focus mainly on the stem size, and lack any relevant information regarding their spatial structure. More importantly, they cannot reliably provide a thinning target in ad-

Spatially explicit algorithms may allow for a higher standard of choice when it comes to tree harvesting. For example, we may be able to measure the structural attributes of specific regions in a forest community or the point density around a single tree (Gadow \& Hui 1998). The cutting intensity of a single harvest can be determined by setting a stand density threshold, but this does not ensure an effective improvement of the forest stand. This is because the tree growth response to thinning is always dependent on the relation-

Managing stand density therefore requires consideration of three properties: species composition, spatial distribution pattern, and tree size (Kint et al. 2003). Any tree in a stand reflects these three proper-
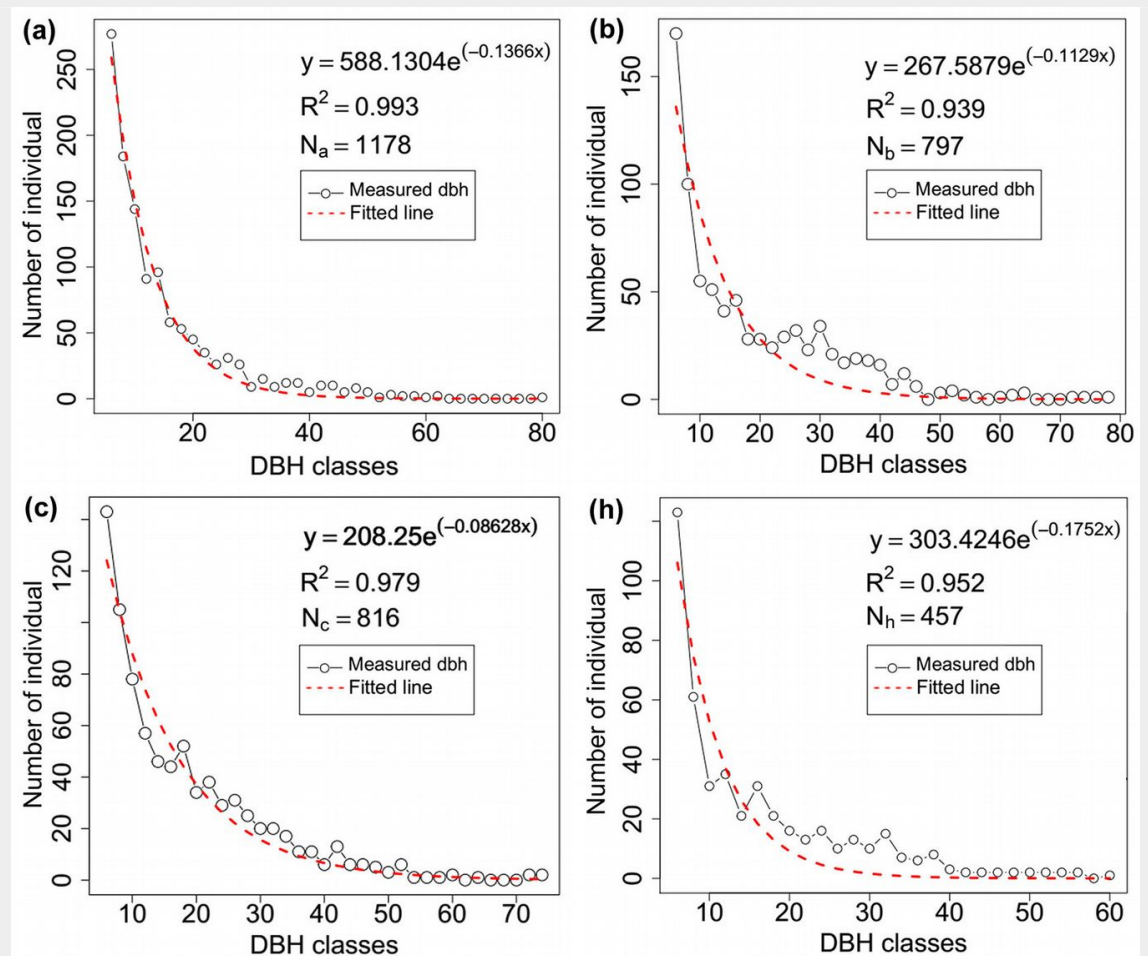

Fig. 1 - Diameter classes of the four measured plots. ties at the same time, and when these attributes are discretized, the stand can be divided into structural "combinations" summarized by any two of these properties (Li et al. 2012). A change in these bivariate characteristics of stand structure may reflect the possibility that cutting trees in a structural combination, namely, a so-called thinning priority, is preferable.

The purpose of our study is to put forward bivariate thinning priority indices based on tree neighbor-spatial relationships. We used these indices to parameterize thinning in Korean pine broad-leaved forests in northeast China and pine-oak mixed forests in northwest China in which a structure-based forest management (SBFM) has been implemented. Our research may provide a reference point for the rapid and accurate selection of trees for harvesting in uneven aged forests in the future. It may list the thinning targets in advance and simplify the processes of thinning when compared with traditional methods.

\section{Materials and methods}

\section{Study areas}

Our test stands were a mixed Korean pine-broadleaved forest in northeast China and a mixed pine-oak forest in northwest China. Both have typical zonal vegetation and human intervention has been absent in both forests for more than 40 years. The Korean pine-broadleaved forest consisted of an approximately 31,562-ha wide area with a rectangular form, and we placed our sampling plots in the $52^{\text {th }}, 53^{\text {th }}$, and $54^{\text {th }}$ compartments which belong to the core area of the forest region in Dongdapo, QianJin Village, Jiaohe, Jilin Province ( $43^{\circ}$ $\left.51^{\prime}-44^{\circ} 05^{\prime} \mathrm{N}, 127^{\circ} 35^{\prime}-127^{\circ} 51^{\prime} \mathrm{E}\right)$. This site has a low-relief topography with mean elevation of $1720 \mathrm{~m}$ a.s.l. and a monsoon climate with dry, windy springs and warm, wet summers, long, cool winters, and sunny autumns. The stands have a relatively undisturbed structure and the canopy cover is about $90 \%$ as determined by visual observation. Pinus koraiensis Sieb. et Zucc., Picea jezoensis var. microsperma (Lindl.), Juglans mandshurica Maxim., and Acer mandshurica Maxim. are the common species in this mixed forest. There are 22 tree species in total and the ratio of conifers to broadleaves approaches 1:9, but the coniferous trees are much bigger than any individual hardwood tree (Li et al. 2012, 2014b) - Tab. 1, Fig. 1).

The pine-oak mixed forest covered about 706,625 ha and our study site is located in the $57^{\text {th }}$ compartment of the Baihua forest farm, on Xiaolong Mountain, Gansu Province $\left(33^{\circ} 30^{\prime}-34^{\circ} 49^{\prime} \mathrm{N}, 104^{\circ} 22^{\prime}-105^{\circ} 43^{\prime} \mathrm{E}\right)$. This region is in a transition area between the warm-temperate zone and the north subtropical zone, and has a diversified climate and four seasons. More than 30 tree species occur in this relatively mature forest, which has a complex structure and 
high biodiversity. Its canopy cover is about $80 \%$. Quercus aliena var. Acuteserrata Maxim., Pinus armandii Franch., Symplocos paniculata (Thunb.) Miq., Quercus liaotungensis Koidz., Ulmus glabta Huds., and Crataegus kansuensis Wils. are the most common species in this particular forest stand (Hui et al. 2010, Li et al. 2014a, 2014b). The ratio of conifers to broadleaves is 1: 10 .

\section{Field measurements}

In 2008-2009, six $100 \times$ 100-m permanent plots were selected and established in the Korean pine broadleaved forest. In each plot, every tree $\geq 5 \mathrm{~cm}$ in diameter at 1.30 $m$ height (DBH) was tagged and positioned and its species was recorded. Three of the plots ( $a, b$, and $c)$ were subsequently harvested in the same year according to the principles of SBFM, whose purpose is to dynamically monitor the successional processes of Korean pine-broadleaf, and to investigate the positive effect of SBFM on forest communities (Hui et al. 2007, Li et al. $2014 \mathrm{~b})$. The main characteristic of techniques is to use the stand structure parameters to select and cut single tree, with the purpose to promote or keep stands within a high mixture, tree size differentiation, and random distribution status that was usually detected in virgin forests. All unhealthy trees were removed from the sampling plots at first. Secondly, trees with low mixture $(M=0.00,0.25)$ or in cluster and overdispersed $(\mathrm{W}=0.00,1.00)$ were selected for potential thinning. Larger trees adjacent to smaller ones $(U=0.0-0.25)$ were also selected to reduce competitive pressure on adjacent trees. Thirdly, trees harvested were further selected from the candidate according to the structure requirement of climax species and associated species of medium to large diameter. The main target species included Korean pine, Abies holophylla Maxim., Abies nephrolepis (Trautv.) Maxim., P. jezoensis, Fraxinus mandshurica Rupr., Phellodendron amurense Rupr., J. mandshurica, Acer mono Maxim., Carpinus cordata I., A. mandshuricum, Acer tegmentosum Maxim., Ulmus laciniata (Trautv.) Mayr., Ulmus japonica (Rehd.) Sarg., and Tilia amurensis Rupr. Within the context of the harvest priorities above, $\mathrm{Li}$ et al. (2014b) reported the detail principle of harvest. The cutting intensity was 9, 13, and $10 \%$ of standing volume for plots (a), (b), and (c), respectively.

Similarly, we set up two $70 \times 70-\mathrm{m}$ permanent plots in the pine-oak mixed forest in 2009-2010, one of which (h) was thinned with the aim of removing mature timber and optimizing stand structure. The whole thinning process was close to that in Korean pine broad-leaved forests. The target species in this stand contained U. glabra, $P$. armandii, Q. liaotungensis, Ace giraldii Pax., S. paniculata, Cerasus polytricha (Koehne) $\mathrm{Yu}$ and $\mathrm{Li}, \mathrm{C}$. kansuensis, and Carya cathayensis Sarg. The cutting intensity was $11 \%$ (Hui et al. 2010, Li et al. 2014b).

\section{Data analysis}

We defined a "structural unit" as a combination of any tree and its four nearest neighbors. Any structural unit can be simultaneously described by several factors, such as tree species, tree size, and distribution in the space. These factors can be well expressed by the stand structure parameters mingling index ( $M$, Hui \& Gadow 2003, Kint et al. 2003 - eqn 1), dominance index (U, Hui et al. 2007, Pommerening 2008 eqn. 2), and uniform angle index ( $W$, Li et al. 2012, Gadow et al. 2012 - eqn. 3). The mingling index refers to the probability of a reference tree to belong to the same species as its four nearest neighbors, and has five possible values: $0.00,0.25,0.50,0.75$, and 1.00. A higher value implies a larger number of species in the structural unit. Dominance index reflects the relationship between the size of a reference tree and its four nearest neighbors. It also has five possible values: $0.00,0.25,0.50,0.75$, and 1.00. A higher value implies that the reference is larger (dominant) than all four neighbors. The uniform angle index indicates the spatial dispersion of the four nearest neighbors around the reference tree. Increasing values $(0.00,0.25,0.50$, 0.75 , and 1.00 ) indicate a transition from regular to random to clumped spatial pattern (Hui \& Gadow 2003, Pommerening 2008, Pastorella \& Paletto 2013).

The mingling index $M$ is calculated as (eqn. 1):

$$
M_{i}=\frac{1}{4} \sum_{j=1}^{4} v_{i j}, v_{i j}= \begin{cases}1 & \text { if } s p_{j} \neq s p_{i} \\ 0 & \text { otherwise }\end{cases}
$$

where $v_{i j}$ takes the value 1 if the $j$-th neighbor $\left(s p_{i}\right)$ does not belong to the same species as the reference tree $i\left(s p_{\mathrm{i}}\right)$, and the value 0 otherwise. The dominance index $U$ is calculated as follows (eqn. 2):

$$
U_{i}=\frac{1}{4} \sum_{j=1}^{4} k_{i j}, k_{i j}= \begin{cases}1 & \text { if } d_{j}<d_{i} \\ 0 & \text { otherwise }\end{cases}
$$

where $k_{\text {ij }}$ takes the value 1 if the $j$-th neighbor $\left(d_{\mathrm{j}}\right)$ is smaller than the reference tree $i$ $\left(d_{i}\right)$, and the value 0 otherwise. The uniform angle index $W$ is (eqn. 3):

$$
W_{i}=\frac{1}{4} \sum_{j=1}^{4} z_{i j}, z_{i j}=\left\{\begin{array}{ll}
1 & \text { if } \alpha_{j}<\alpha_{0}=72 \\
0 & \text { otherwise }
\end{array}\right. \text { 。 }
$$

where $z_{\mathrm{ij}}$ takes the value 1 if the $\alpha$ angle is smaller that $\alpha_{0}=72^{\circ}$, and the value o otherwise.

These stand structure parameters have clear biological significance and can be rapidly assessed in the field, making the selection of candidate trees possible by evaluating the relationship between each reference tree and its four nearest neighbors. When any two parameters are joined together, three bivariate distributions of stand structure parameters can be obtained: mingling-dominance $(\mathrm{M}-\mathrm{U})$, mingling-uniform angle index (M-W), and dominance-uniform angle index (U-W). Each joint probability includes $25(5 \times 5)$ types of structural combinations ( Li et al. 2012). Corresponding to the bivariate distributions of stand structure parameters, three thinning priority indices $\left(P r_{\mathrm{ii}}\right)$ are obtained if we divide the probability of each structural combination of harvested wood and that of the total stand before the cut, namely, $v i j, k_{-} i j$ and $z_{-} i j$. Each of them includes two main attributes of tree species relating to thinning and the results can reflect trees that are likely to be selected in different structural combinations. The greater priority value implies a higher probability of selection. Foresters could also use these thinning priority indices to predict the trees to be cut under the conditions of similar thinning rules. Thinning priorities for each bivariate value of the three indices were computed ex-post in each harvested plot (a-h) according to the following equations (eqn. 4, eqn. 5, eqn. 6, eqn. 7):

$$
\begin{aligned}
\rho_{i j} & =\frac{n_{i j(h)}}{N_{h}} \\
p_{i j} & =\frac{n_{i j(b h)}}{N_{t o t}} \\
k_{i j} & =\frac{n_{i j(h)}}{N_{t o t}} \\
\operatorname{Pr}_{i j} & =\frac{\rho_{i j}}{p_{i j}} \cdot k_{i j}
\end{aligned}
$$

where $P r_{\mathrm{ij}}$ is the thinning priority index of structural combination $i j$ (higher values = tree more intensely selected for removal); $\rho_{\mathrm{ij}}$ is the proportion of harvested trees in structural combination $i j$ (i.e., the total number of trees harvested were divided by each in the structural combination of trees harvested); $p_{\mathrm{ij}}$ is the proportion of trees in structural combination $i j$ before harvest (i.e., the total number of trees were divided by each in the structural combination of the whole plot before harvest); $n_{\mathrm{i}(\mathrm{h})}$ is the number of trees in the structural combination of trees harvested; $N_{(\mathrm{h})}$ is the total number of harvested trees; $n_{\mathrm{i}(\mathrm{(bh})}$ is the number of trees in the structural combination of the whole plot before thinning; $N_{\text {tot }}$ is the total number of trees before harvest; $i=0.00,0.25,0.50,0.75,1.00 ; j=0.00,0.25$, $0.50,0.75,1.00$.

\section{Results}

$v_{-}$ij of the four managed plots

In plot (a), approximately half of the trees were assigned to a high selection priority $\left(P r_{\mathrm{ij}}>10 \%\right)$ based on high dominance index of neighbors ( $U=0.75$ and 1.00), accounting for $51.4 \%$ of the whole plot and high species mingling index $(M=0.75$ and 1.00 ), representing $66.4 \%$ of all trees across the 25 structural combinations (Fig. 2a). In plots (b) and (c) the priority index was similarly distributed, with a maximum of $24 \%$, and increased with increasing the mingling index. The highest values occurred for combinations of $M=1.00 / U=0.75$ and $M=$ $1.00 / U=0.50$, respectively, and were 7.6 


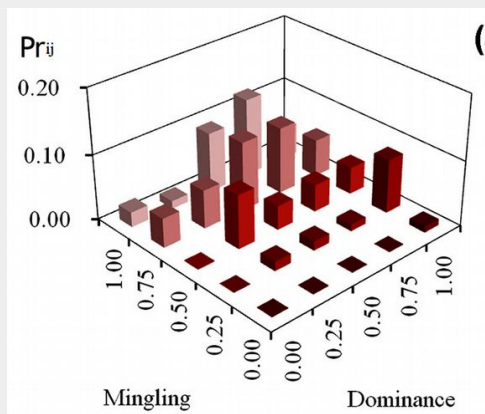

(a)

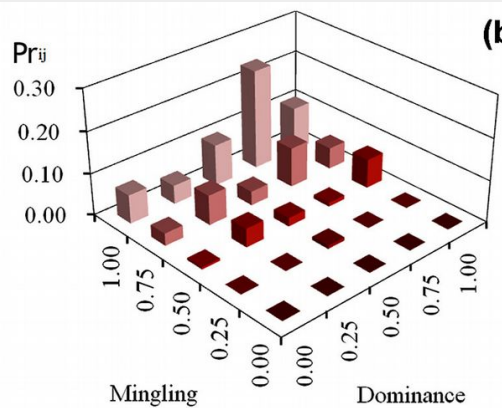

(b) Fig. 2 - $v \_i j$ values of trees in four managed plots.

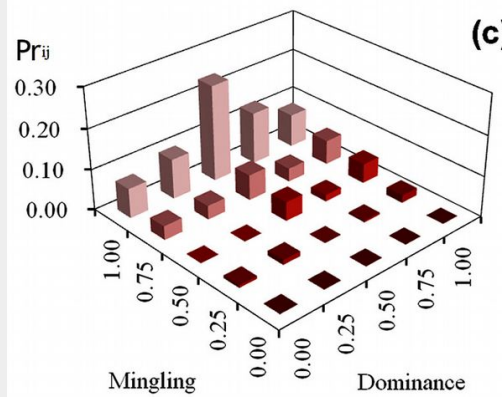

(c)

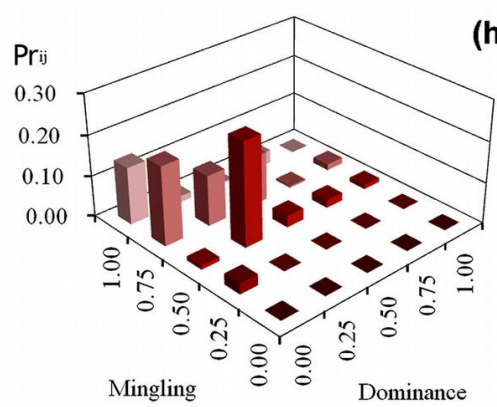

(h)

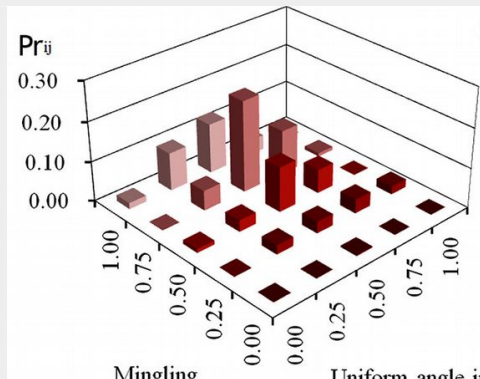

(a)

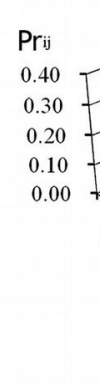

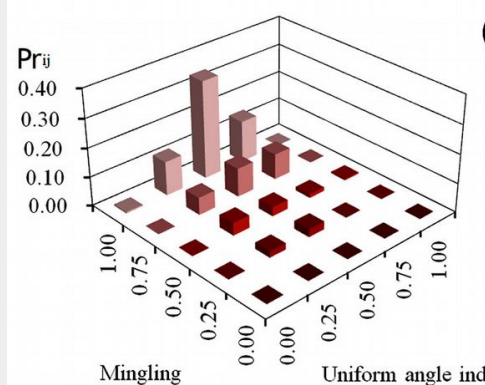

(c)
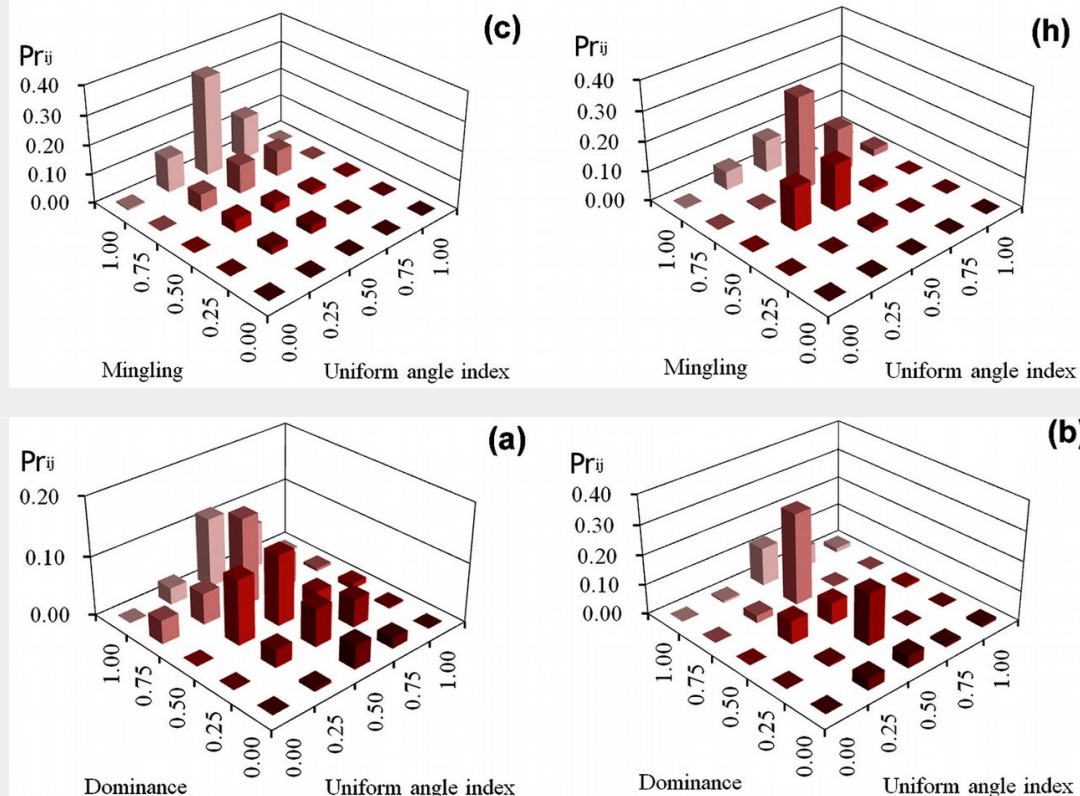

(a)

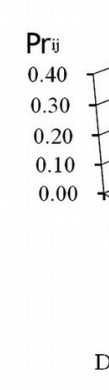

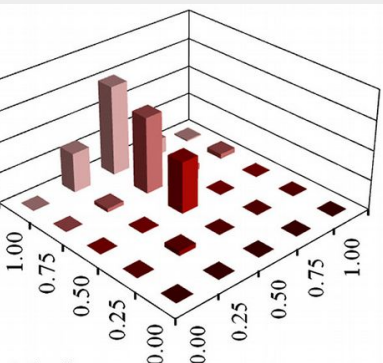

(b) Fig. 3- $k \_i j$ values of trees in four managed plots.

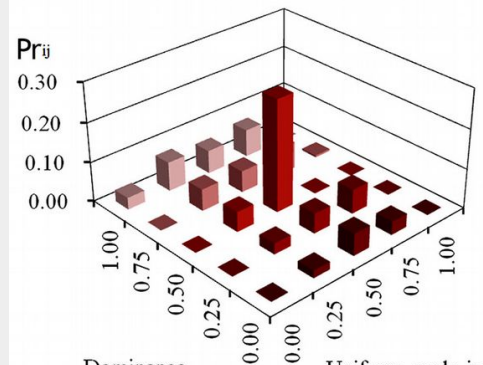

(c)

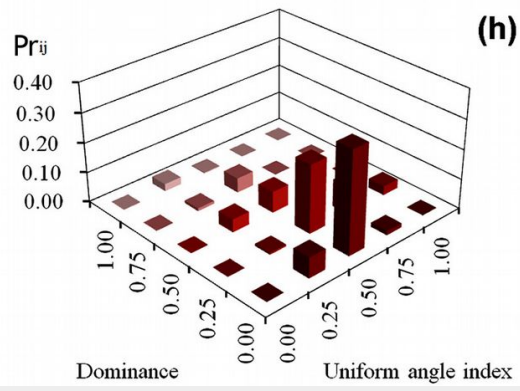

(b) Fig. $4-z \_i j$ values of trees in four managed plots. 
times higher than the average priority index of the other 23 structural combinations (Fig. 2b, Fig. 2c). The highest priority indices in plot (h) were primarily associated to two kinds of structural combinations, $M$ $=0.75 / U=1.00$ and $M=0.50 / U=0.25$, accounting for 19.4 and $25.5 \%$ of all trees in the plot, and were 9.9 and 13 times higher, respectively, than the average of the residual 23 structural combinations (Fig. 2h).

\section{k_ij of the four managed plots}

Most high $M-W$ priority indices in plots (a), (b), (c), and (h) were associated to $W=$ 0.50 , accounting for $50.1 \%, 74.0 \%, 50.0 \%$, and $60.0 \%$, respectively of all trees in each plot (Fig. 3), and to $M=0.75$ and 1.00 (67.7\%, $80.7 \%, 85.7 \%$, and $67.0 \%$ of trees in plots a, b, c, and h, respectively). The highest priority index values in plots (h) and (a) were $23.0 \%$ and $30.6 \%$, respectively $(M=$ $0.75 / \mathrm{W}=0.50$ ), while in plots (b) and (h) they were $34.1 \%$ and $31.9 \%$, respectively $(M$ $=1.00 / W=0.50)$. In addition, approximately $87.4 \%$ and $77.4 \%$ of the trees in plots (b) and (h) were concentrated in four structural combinations, while $60.4 \%$ of the trees in plot (c) were concentrated in three structural combinations (Fig. 3).

\section{z_ij of the four managed plots}

In plot (a), approximately $94 \%$ of the trees had $W=0.25$ to 0.75 , while only $6.0 \%$ exhibited a clumped $(W=1.00)$ or regular $(W=0.00)$ distribution of neighbors (Fig. 4). High priority indices also fell on the subdominant and suppressed reference trees ( $U=0.50-1.00$ ), making up $79.2 \%$ of the whole plot. The highest priority in plots (b), (c), and (h) was assigned to trees with $W=$ $0.50(72.8 \%, 50.2 \%$, and $69.8 \%$ of the trees, respectively); among them, $48.3 \%$ of the trees in plot (b) occurred in two structural combinations: $U=0.75 / W=0.50$ and $U=$ $0.25 / W=0.50$, while the highest priority index in plot (c) was at structural combination $U=0.50 / W=0.50$ (28.2\% of the trees in the plot). The two highest indices in plot (h) occurred at the structural combinations $U=0.25 / W=0.50$ and $U=0.00 / W=0.50$, and together made up $57.5 \%$ of the plot. Their mean value was much greater than the average of the residual 23 structural combinations.

\section{Discussion}

Thinning directly influences tree growth, mortality, spatial distribution, and species diversity. In SBFM, the selection of trees to be cut within each structural unit is determined by the spatial relationship between a tree and its neighbors, including factors such as tree species, size, and spatial pattern. The close connection between these factors makes the process of selection direct and simple, and the application of this method to the management of natural forests has achieved some success (Hui et al. 2010, Gadow et al. 2012, Li et al. 2014b). The thinning priority indices proposed in this paper can determine what characteris- tics of trees are preferred and can be used as quantitative tools to apply or simulate thinning in uneven-aged, mixed forests.

Three types of priority indices, in the form of bivariate distributions, described the probability to be selected for harvest of trees in four sample plots. $v$ i $i$ indicated that high-priority trees selected for removal were usually surrounded by trees of different species, and their social status ranged from subdominant to suppressed (except in mixed pine-oak forest where subdominant trees in medium mixtures and dominant trees in high mixtures were chosen). $k$ _ $i j$ showed that trees in high mixtures and random distributions were most likely to be cut. $z \_i j$ implied that thinned trees had usually randomly distributed neighbors, while their status ranged from suppressed (plots a-c, Korean pinebroadleaved forest) to dominant (plot h, pine-oak forest).

These results are closely related to the development phase and the structure characteristics of a stand before a cut. The Korean pine broadleaved forest and pine-oak mixed forest were natural secondary stands that had gone without large disturbances for long periods of time and showed random stem distribution patterns and high levels of tree size differentiation. Therefore, many trees selected for harvest from these plots were likely to be randomly surrounded by or mixed with other species. The thinning steps effetely improved the whole mixture and kept four stands in random pattern (Li et al. 2014b). At the same time, because of the structural diversity of the stands, it is impossible for thinning to concentrate only on a single structural combination. However, in each plot exists a particular structural combination with a higher priority for selection, which may be indicative of the thinning criteria to be followed in similar forest stands and for similar management objectives. i.e., remove unhealthy individuals, prioritize tree size differentiation, and at the same time harvest commercially sized trees. Thus, the subdominant and dominant individuals became the preferred candidates.

A similar thinning priority index based on the joint probability distribution of species mingling index $(M)$ and diameter differentiation $(T)$ has been suggested in a Fagus sylvatica L. and Picea abies (L.) Karst. mixed forest in Southern Germany (Gadow \& Hui 1998, Gadow et al. 2012). The thinning priority indices proposed in this study have a similar structure to such $M-T P r_{\mathrm{i}}$, but their application in the field is more straightforward, and they correct one of its shortcomings, i.e., they take into account the change in the actual number of trees in each structural combination before and after the thinning.

\section{Conclusion}

Selecting trees for harvest from an uneven-aged mixed forest is a complex deci- sion-making process. Appropriately quantifying stand structure characteristics and objectives when thinning, including tree spatial patterns, may help to achieve sustainable forest management practices. Following the application of SBFM, the thinning priority indices put forward in this study adequately describe the spatial relationship between each tree and its nearest neighbors and treat bivariate structural combinations as basic thinning units when describing the thinning priority of harvested trees with different structural characteristics. Their application can reduce the subjectivity and improve the speed and accuracy of the choice of trees to be harvested in uneven-aged mixed forests. The benefit of using these indices is that the multi-faceted relationships among trees are clearly defined, with a directly relationship to the choice of trees to cut. Thinning priority indices may be suitable for application in different types of forest, and require a full investigation of the whole stand before they can be applied to management decisions. Different priorities are likely to emerge from the combination of thinning index, stand structure and management goals, therefore the implications of choosing one or another of the thinning priority indices as the basis for forest density management may need further research.

\section{List of abbreviations}

The following abbreviations have been used throughout the text:

- $W$ : uniform angle index;

- M: mingling index;

- $U$ : dominance index;

- DBH: diameter at breast height;

- SBFM: structure-based forest management;

- T: diameter differentiation.

\section{Acknowledgments}

This paper was financially supported by National Sci-Tech Support Plan of China (2012BAD22B03) and National Science Foundation of China (No.31400542). Hongxiang Wang and Gongqiao Zhang carried out the field measurements, Shaoming Ye performed the statistical analysis, Gangying Hui conceived the study and helped to draft the manuscript, Yuanfa Li wrote and finished the manuscript.

\section{References}

Cogliastro A, Paquette A (2012). Thinning effect on light regime and growth of under planted red oak and black cherry in post-agricultural forests of south-eastern Canada. New Forests 43: 941-954. - doi: 10.1007/s11056-012-9329-5

Del Río M, Calama R, Cañellas I, Roig S, Montero $G$ (2008). Thinning intensity and growth response in SW-European Scots pine stands. Annals of Forest Science 65 (3): 308. - doi: 10.1051/ forest:2008009

Dung BX, Gomi T, Miyata S, Sidle RC, Kosugi K (2012). Runoff responses to forest thinning at plot and catchment scales in a headwater catchment draining Japanese cypress forest. 
Journal of Hydrometeorology 444-445: 51-62. doi: 10.1016/j.jhydrol.2012.03.040

Franklin JF, Mitchell RJ, Palik BJ (2007). Natural disturbance and stand development principles for ecological forestry. General Technical Report NRS-19, Northern Research Station, USDA Forest Service, Delaware, USA, pp. 44. [online] URL: http://www.fs.fed.us/nrs/pubs/gtr lgtr_nrs19.pdf

Gadow KV, Hui G (1998). Modelling forest development. Kluwer Academic Publishers, Dordrecht, Netherlands, pp. 51-300.

Gadow KV, Zhang C, Wehenkel C, Pommerening A, Corral-Rivas J, Korol M, Myklush S, Hui G, Kiviste A, Zhao X (2012). Forest structure and diversity. Springer, Berlin, Germany, pp. 30-62. doi: 10.1007/978-94-007-2202-6_2

Grayson SF, Buckley DS, Henning JG, Schweitzer CJ, Gottschalk KW (2012). Understory light regimes following silvicultural treatments in central hardwood forests in Kentucky, USA. Forest Ecology and Management 279: 66-76. doi: 10.1016/j.foreco.2012.05.017

Gronewold CA, D'Amato AW, Palik BJ (2010). The influence of cutting cycle and stocking level on the structure and composition of managed oldgrowth northern hardwoods. Forest Ecology and Management 259: 1151-1160. - doi: 10.1016/j. foreco.2010.01.001

Hui G, Gadow KV (2003). Quantitative analysis of forest spatial structure. China Science and Technology Press, Beijing, China, pp. 16-18.

Hui G, Gadow KV, Hu Y, Xu H (2007). Structurebased forest management. China Forestry Publishing House, Beijing, China, pp. 28-70.

Hui G, Zhao Z, Hu Y (2010). A guide to structurebased forest management. China Forestry Publishing House, Beijing, China, pp. 20-144.

Kang X (2011). Forest management. China Forestry Publishing House, Beijing, China, pp. 230236.

Kint V, Meirvenne MV, Nachtergale L, Geuden G, Lust N (2003). Spatial methods for quantifying forest stand structure development: a comparison between nearest-neighbors indies and variogram analysis. Forest science 49: 36-49. [online] URL: http://www.ingentaconnect.com/con tent/saf/fs/2003/00000049/00000001/art00003 Kuuluvainen T, Penttinen A, Leinonen K, Nygren M (1996). Statistical opportunities for comparing stand structural heterogeneity in managed and primeval forests: an example from boreal spruce forests in Southern Finland. Silva Fennica 30: 315-328. - doi: 10.14214/sf.a9243

Kyereh B, Swaine MD, Thompson J (1999). Effect of light on the germination of forest trees in Ghana. Journal of Ecology 87: 772-783. - doi: 10.1046/j.1365-2745.1999.00386.x

Li Y, Hui G, Zhao Z, Hu Y (2012). The bivariate dis- tribution characteristics of spatial structure in natural Korean pine broad-leaved forest. Journal of Vegetation Science 23: 1180-1190. - doi: 10.1111/j.1654-1103.2012.01431.X

Li Y, Hui G, Zhao Z, Hu Y, Ye S (2014a). Spatial structural characteristics of three hardwood species in Korean pine broad-leaved forest Validating the bivariate distribution of structural parameters from the point of tree population. Forest Ecology and Management 314: 1725. - doi: 10.1016/j.foreco.2013.11.012

Li Y, Ye S, Hui G, Hu Y, Zhao Z (2014b). Spatial structure of timber harvested according to structure-based forest management. Forest Ecology and Management 322: 106-116. - doi: 10.1016/j.foreco.2014.02.042

Lindenmayer DB, Cunningham RB, Donnelly CF, Franklin JF (2000). Structural features of oldgrowth Australian montane ash forests. Forest Ecology and Management 134: 189-204. - doi: 10.1016/S0378-1127(99)00257-1

Long JN, Vacchiano G (2014). A comprehensive framework of forest stand property-density relationships: perspectives for plant population ecology and forest management. Annals of Forest Science 71: 325-335. - doi: 10.1007/s13595-01 3-0351-3

Lyons KG, Brigham CA, Traut BH, Schwartz MW (2004). Rare species and ecosystem functioning. Conservation Biology 19: 1019-1024. - doi: 10.1111/j.1523-1739.2005.00106.x

Ma K (1999). Ecosystem diversity of warm temperate deciduous broad-leaved forest in Dongling Mountain. In: "Ecosystem diversity in key areas of China" (Ma K ed). Zhejiang Science and Technology Press, Hangzhou, China, pp. 532108.

Mäkinen H, Isomäki A (2004). Thinning intensity and growth of Scots pine stands in Finland. Forest Ecology and Management 201: 311-325. - doi: 10.1016/j.foreco.2004.07.016

Mazza G, Amorini E, Cutini A, Manetti MC (2011). The influence of thinning on rainfall interception by Pinus pinea L. in Mediterranean coastal stands (Castel Fusano - Rome). Annals of Forest Science 68: 1323-1332. - doi: 10.1007/s13595011-0142-7

McHenry MT, Wilson BR, Lemon JM, Donnelly DE, Growns IG (2006). Soil and vegetation response to thinning White Cypress pine (Callitris glaucophylla) on the north western slopes of New South Wales, Australia. Plant and Soil 285: 245-255. - doi: 10.1007/s11104-006-9011-9 Mills LS, Soulé ME, Doak DF (1993). The keystone-species concept in ecology and conservation. Bioscience 43: 219-224. - doi: 10.2307/13 12122

Myers GP, Newton AC, Melgarejo O (2000). The influence of canopy gap size on natural regen- eration of Brazil nut (Bertholletia excelsa) in Bolivia. Forest Ecology and Management 127: 119-128. - doi: 10.1016/S0378-1127(99)00124-3

Nahm M, Holst T, Matzarakis A, Mayer H, Rennenberg $\mathrm{H}$, Gessler A (2006). Soluble N compound profiles and concertrations in European beech (Fagus sylvatica L.) are influenced by local climate and thinning. European Journal of Forest Research 125: 114. - doi: 10.1007/s10342005-0103-5

Negro M, Vacchiano G, Berretti R, Chamberlain DE, Palestrini C, Motta R, Rolando A (2014). Effects of forest management on ground beetle diversity in alpine beech (Fagus sylvatica L.) stands. Forest Ecology and Management 328: 300-309. - doi: 10.1016/j.foreco.2014.05.049

Nowak J, Asaro C, Klepzing K, Billings R (2008). The southern pine beetle prevention initiative: working for health forests. Journal of Forestry 106: 261-267. [online] URL: http://www.ingenta connect.com/content/saf/jof/2008/00000106/0 $0000005 /$ arto0004

O'Hara KL (2007). Integrating dynamics into management of complex forests: seeking balance in an unbalanced world. In: Proceedings of the Conference "Complex Stand Structures and Associated Dynamics: Measurement Indices and Modelling Approaches". Sault Ste. Marie (Ontario, Canada), 29 Jul-2 Aug 2007. Ontario Forest Research Institute, Sault Ste. Marie, Ontario, Canada, pp. 20.

Pastorella F, Paletto A (2013). Stand structure indices as tools to support forest management: an application in Trentino forests (Italy). Journal of Forest Science 59: 159-168. [online] URL: http://www.researchgate.net/publication/2367 36373

Pommerening A (2008). Analyzing and modelling spatial woodland structure. PhD thesis, Bangor University, Bangor, Maine, UK, pp. 36227.

Qiu S, Bell RW, Hobbs RJ, McComb AJ (2013). Overstorey and juvenile response to thinning and drought in a jarrah (Eucalyptus donnex Sm.) forest of southwestern Australia. Plant and Soil 365: 291-305. - doi: 10.1007/s11104-012-1368-3 Schulte BJ, Buongiorno J (1998). Effects of uneven-aged silviculture on the stand structure, species composition, and economic returns of loblolly pine stands. Forest Ecology and Management 111: 83-101. - doi: 10.1016/S0378-1127 (98)00312-0

Tao D, Li Y, Lu D, Luo Y, Yu S, Ye S (2016). The essential oil components of Cinnamomum cassia: an analysis under different thinning models of plantation Pinus massoniana. Journal of Forestry Research 3: 707-717. - doi: 10.1007/s11676015-0192-z 